\title{
Serum amyloid A protein and C-reactive protein levels in pulmonary tuberculosis: relationship to amyloidosis
}

\author{
FC DE BEER, AE NEL, RP GIE, PR DONALD, AF STRACHAN
}

From the Departments of Internal Medicine and Paediatrics, University of Stellenbosch Medical School, Tygerberg, South Africa

ABSTRACT C-reactive protein and serum amyloid A protein levels were measured in 54 patients with pulmonary tuberculosis. The primary tuberculous complex was associated with an insignificant acute phase response, while post-primary tuberculosis without evidence of lung destruction caused modest increases in C-reactive protein and serum amyloid A protein. In most patients with post-primary pulmonary tuberculosis with significant pulmonary destruction there was a major acute phase response, with very high serum amyloid A protein and C-reactive protein levels. The response in these patients is most likely to be due to secondary bacterial infection in addition to infection by Mycobacterium tuberculosis. Patients with miliary tuberculosis showed a major acute phase response. Serum amyloid A protein and C-reactive protein levels decreased rapidly after initiation of treatment in the patients with post-primary tuberculosis without significant pulmonary destruction.

C-reactive protein and serum amyloid A protein are the most sensitive and dramatically rising acute phase proteins in man. With the advent of sensitive assays for these proteins their value in the diagnosis and management of disease processes merits study. $\mathrm{C}$-reactive protein is a hepatically produced cyclic pentameric protein whose function is unknown, although it is believed to be concerned in the clearance of autogenous and exogenous material from the circulation.' Serum amyloid A protein exists in its native state in the plasma as a high molecular weight form mainly associated with high density lipoprotein and behaving as an apolipoprotein. ${ }^{2}$ Proteolytic cleavage of the C-terminal portion of serum amyloid $\mathrm{A}$ protein yields amyloid $\mathrm{A}$ protein, which forms the fibrils in reactive systemic amyloidosis. ${ }^{34}$ Tuberculous infection has classically been associated with the development of secondary amyloidosis. ${ }^{5} \mathrm{C}$-reactive protein concentrations in seven patients with tuberculosis have previously been studied by means of an inadequate semiquantitative assay. ${ }^{\circ}$ When this assay was used

Address for reprint requests: Dr FC de Beer, Department of Internal Medicine, PO Box 63, Tygerberg 7505, South Africa

Accepted 29 November 1983
$\mathrm{C}$-reactive protein was detectable in three of the seven patients. Serum amyloid A protein levels have not been studied previously in tuberculosis.

\section{Methods}

Single serum samples were obtained for routine management at the time of diagnosis from 54 patients with pulmonary tuberculosis of various types, and studied retrospectively. Eleven patients were black and 42 of mixed race (Cape coloured). Tuberculosis was categorised as follows:

Group 1 Fourteen patients (aged 1-6 years) had a primary tuberculous complex and no clinically detectable additional disease.

Group 2 Twelve patients (aged 17-42 years) had post-primary tuberculosis with no radiologically significant pulmonary destruction. With conventional immunofluorescent techniques Mycobacterium tuberculosis was detected in the sputum of all the patients. Complete radiological resolution occurred in all patients within three months of their starting treatment.

Group 3 Sixteen patients (aged 24-53 years) had post-primary tuberculosis proved by positive sputum immunofluorescence, with radiological evidence of pulmonary destruction (cavitation, exten- 
sive fibrosis, lobar destruction, or bronchiectasis). Group 4 Six patients (aged 3 months-13 years) had miliary tuberculosis with pulmonary lesions. Group 5 Six patients (aged 18-27 years) had post-primary tuberculosis and a pleural exudate, with no other signs of tuberculous disease. The diagnosis was made from the presence of Mycobacterium tuberculosis in the sputum or pleural fluid or from positive histological findings at pleural biopsy.

Serial samples (days $0,2,5$, and 10 after initiation of treatment) were available from eight group 2 patients with post-primary tuberculosis without pulmonary destruction (figs 1 and 2) and from 11 group 3 patients with extensive pulmonary destruction (figs 1 and 3). All patients treated received a four drug antituberculosis regimen of rifampicin, isoniazid, pyrazinamide, and ethambutol or ethionamide.

Serum was separated from venous blood clotted at room temperature and stored at $-20^{\circ} \mathrm{C}$. $\mathrm{C}$-reactive protein concentrations were measured by means of a magnetisable cellulose solid phase immunoradiometric assay standardised to pure isolated human C-reactive protein.' Among 468 sera from normal adult volunteer blood donors the median C-reactive protein concentration was 800 $\mu \mathrm{g} / \mathrm{l}$, with $90 \%$ of samples containing less than 3 $\mathrm{mg} / \mathrm{l}$ and $99 \%$ less than $10 \mathrm{mg} / 1 .{ }^{8}$ Serum amyloid $A$ protein levels were measured with a similar immunoradiometric assay with standardisation in arbitrary units per litre. ${ }^{9}$ Of 100 sera from healthy volunteer blood donors two had levels below the sensitivity of the assay $(1 \mathrm{U} / \mathrm{l})$ and $93 \%$ lower than $20 \mathrm{U} / 1,{ }^{9}$ while the highest level was $100 \mathrm{U} / \mathrm{l}$.

The statistical significance of differences between groups was sought by Wilcoxon rank sum tests.

\section{Results}

\section{C-REACTIVE PROTEIN AND SERUM AMYLOID A PROTEIN LEVELS AT DIAGNOSIS}

$C$-reactive protein and serum amyloid $A$ protein levels at diagnosis (table) correlated well $(\mathrm{r}=0 \cdot 89)$. The acute phase response, as measured by C-reactive protein and serum amyloid $A$ protein concentrations, varied considerably with the various forms of tuberculosis (fig 1).

Patients in group 1, with a primary complex only, mounted a very limited acute phase response, with median values of $25 \mathrm{U} / \mathrm{l}$ for serum amyloid A pro-

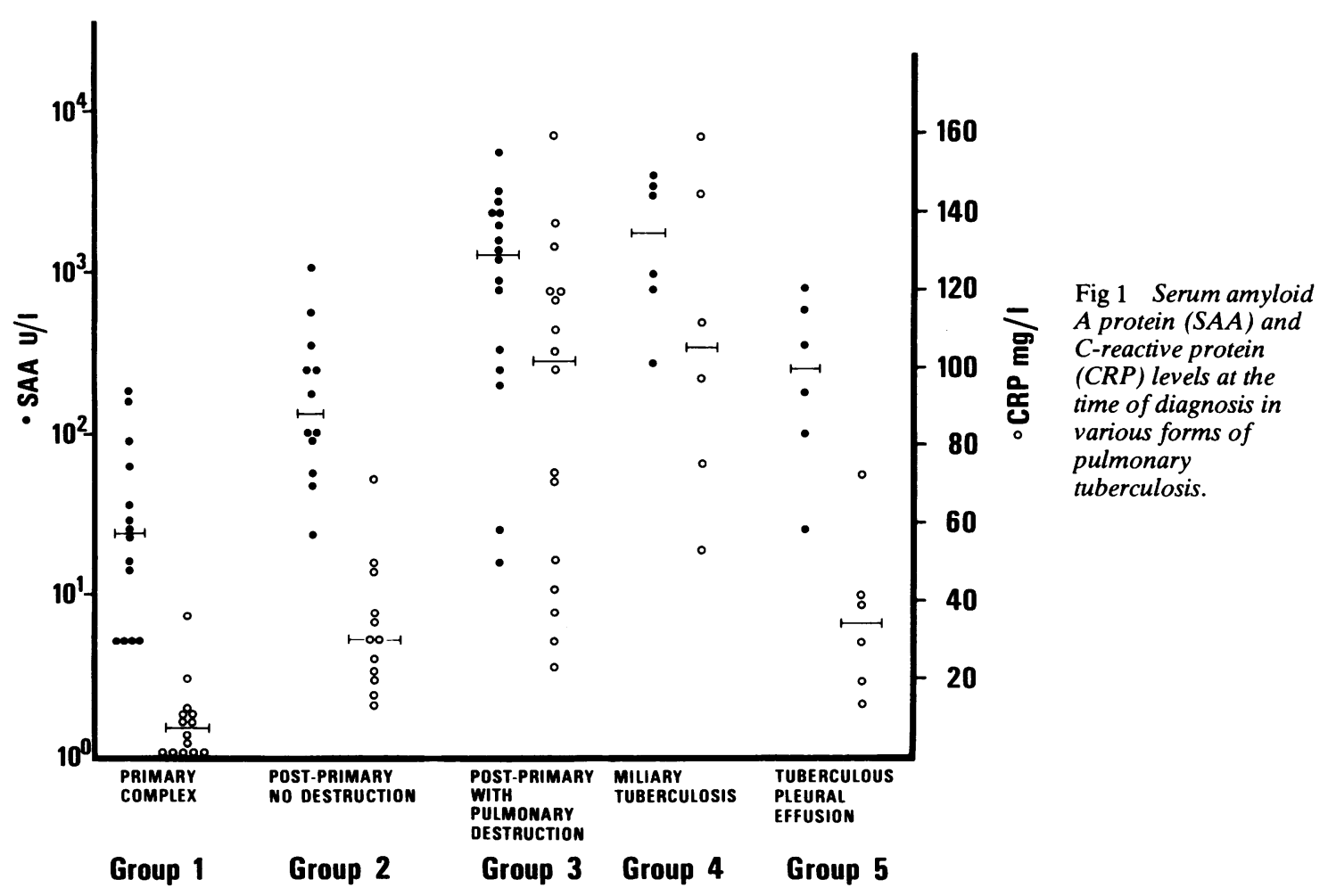




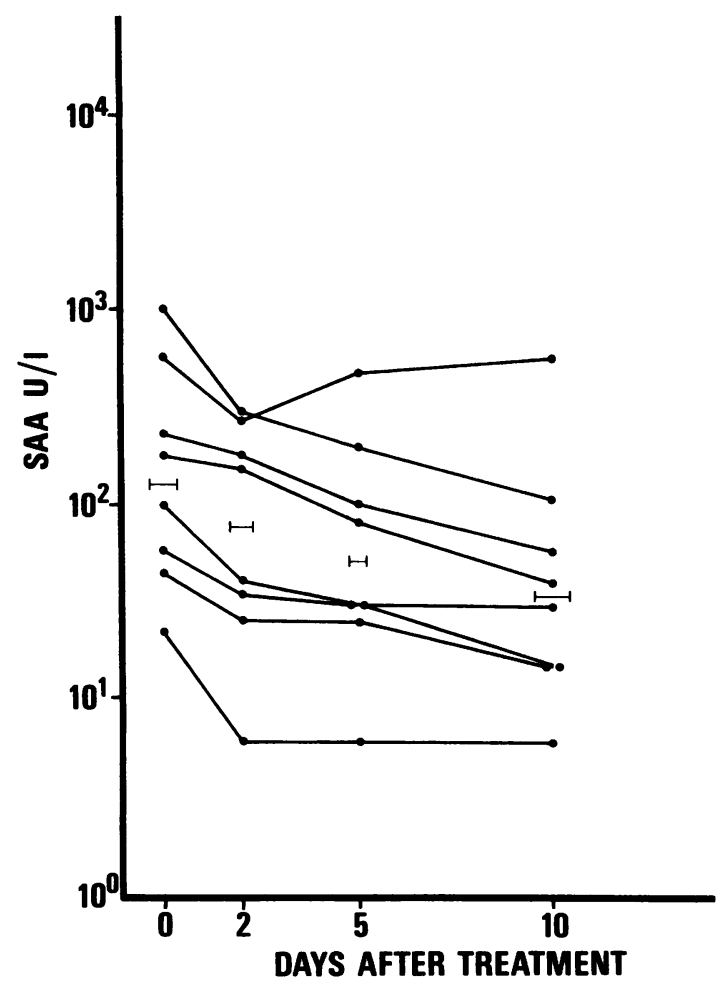

Fig 2 Serum amyloid A protein levels after treatment in patients without overt pulmonary destruction (group 2)

tein and $6.5 \mathrm{mg} / \mathrm{l}$ for C-reactive protein. Group 2 patients, with post-primary tuberculosis without overt pulmonary destruction, showed a modest acute phase response (median values $140 \mathrm{U} / \mathrm{l}$ for serum amyloid A protein and $30 \mathrm{mg} / \mathrm{l}$ for $\mathrm{C}$-reactive protein. The serum amyloid $A$ protein and $\mathrm{C}$-reactive protein levels in this group were significantly higher $(p<0.01)$ than in patients with primary complex tuberculosis. In group 3 patients with severe pulmonary destruction, a major acute phase response was mounted, with median values of $1350 \mathrm{U} / \mathrm{l}$ for serum amyloid A protein and $102 \mathrm{mg} / \mathrm{l}$ for C-reactive protein. Both serum amyloid A protein and $\mathrm{C}$-reactive protein levels spanned a wide

Serum amyloid $A$ protein $(S A A)$ and $C$-reactive protein (CRP) values in the five groups of patients

\begin{tabular}{lccccc}
\hline Group $^{*}$ & \multicolumn{2}{l}{$S A A(U / l)$} & & \multicolumn{2}{c}{$C R P(m g / l)$} \\
\cline { 2 - 3 } \cline { 5 - 6 } & Median & Range & & Median & Range \\
\hline 1 & 25 & $6-180$ & $6 \cdot 5$ & $0 \cdot 3-36$ \\
2 & 140 & $25-1100$ & 30 & $13-71$ \\
3 & 1350 & $17-5700$ & & 102 & $23-160$ \\
4 & 2100 & $280-4000$ & & 105 & $54-160$ \\
5 & 270 & $25-800$ & & 35 & $14-73$ \\
\hline
\end{tabular}

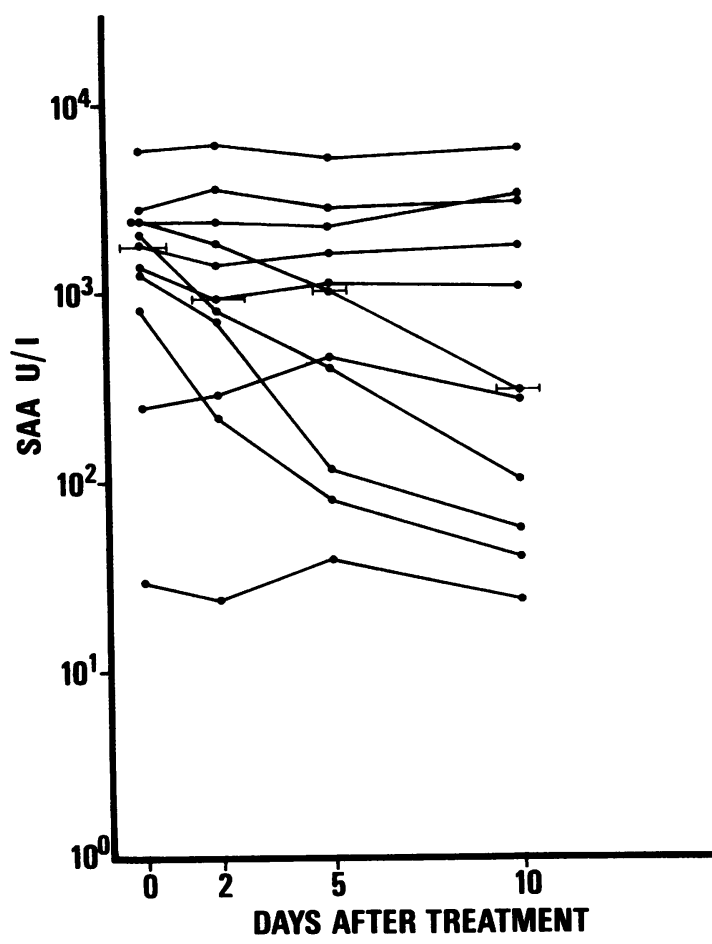

Fig 3 Serum amyloid A protein levels after treatment in patients with pulmonary destruction (group 3).

range, but were significantly higher than in group 2 patients without lung destruction $(p<0.001)$. Patients with miliary tuberculosis (group 4) also had very high levels, with median values of $2100 \mathrm{U} / \mathrm{l}$ for serum amyloid $A$ protein and $105 \mathrm{mg} / \mathrm{l}$ for C-reactive protein. These did not differ significantly from those of patients in group 3 with pulmonary destruction.

Patients presenting with tuberculosus pleural effusion (group 5) had some increase in serum amyloid $\mathrm{A}$ protein and $\mathrm{C}$-reactive protein levels, with median values of $270 \mathrm{U} / \mathrm{l}$ and $35 \mathrm{mg} / \mathrm{l}$. These do not differ significantly from those in group 2 (pulmonary tuberculosis without destruction).

\section{SERIAL SERUM AMYLOID A PROTEIN AND C-REACTIVE PROTEIN LEVELS AFTER TREATMENT}

Serum amyloid A protein levels in seven of the eight patients in group 2 with no overt pulmonary destruction who were studied serially showed a consistent decline towards normal values over 10 days (fig 2 ). The levels two days after initiation of treatment were significantly lower than at diagnosis $(p<0.01)$ 
but did not differ significantly from levels 10 days after treatment had started. In the patient in whom levels did not decline failure to observe the prescribed treatment regimen was suspected, though radiological clearance did result after three months.

Only four of the 11 patients with extensive pulmonary destruction studied serially showed a decrease in serum amyloid A protein levels over the first 10 days (fig 3 ). In the other seven patients the levels remained raised. In all 11 patients sputum became negative for tuberculosis. Serum amyloid A protein levels at two, five, and 10 days after the start of treatment did not differ significantly.

Serial measurements of $\mathrm{C}$-reactive protein showed changes which were almost identical to those of serum amyloid $\mathrm{A}$ protein in individual patients, declining in the seven patients with no overt pulmonary destruction and in only four of the patients with pulmonary destruction (data not shown).

\section{Discussion}

The development of reactive systemic amyloidosis is preceded by a chronic inflammatory state, with high serum amyloid A protein levels maintained over an extended period. In susceptible individuals serum amyloid A protein is enzymatically cleaved to amyloid A protein, which forms the fibrils of secondary amyloidosis. ${ }^{34}$ Chronic inflammatory disease processes such as systemic lupus erythematosus and ulcerative colitis, which cause an insignificant acute phase response with minimal production of serum amyloid A protein, are virtually never complicated by secondary amyloidosis. ${ }^{10}$

Primary complex tuberculosis does not cause a significant acute phase response. These children are often malnourished and the small increases in serum amyloid A protein seen occasionally could be caused by concomitant subclinical bacterial infection. With isolated pleural effusion or pulmonary infiltrates without lung destruction there was only a modest acute phase response. It seems unlikely that these modest increases in serum amyloid A protein would be sufficient to be amyloidogenic in susceptible individuals even if maintained over a period of time.

It seems more probable that the very high serum amyloid A protein levels seen in many patients with severe pulmonary destruction could lead to amyloidosis. The extended range of serum amyloid A protein levels in these patients in group 3 (17$5700 \mathrm{U} / \mathrm{l})$ is likely to reflect the heterogeneity of their infective states. The major acute phase response in these patients is probably caused by a combination of extensive infection with $M$ tuberculosis and secondary bacterial infection. The rapidly declining serum amyloid A protein levels in four of the patients in this group with severe destruction could be explained by effective treatment of $M$ tuberculosis in the absence of secondary bacterial infection. The seven patients who did not respond may have had significant secondary bacterial infection. The major acute phase response in patients with miliary tuberculosis probably reflects the systemic nature of the disease.

The rapid decrease in serum amyloid $A$ protein levels after treatment in patients with minimal pulmonary destruction may indicate effective treatment. Antituberculous treatment is sometimes given diagnostically to patients with a suspicious radiological appearance but no positive evidence of $M$ tuberculosis on the basis of existing bacteriological techniques. Our results suggest that the efficacy of such treatment might be monitored by $\mathrm{C}$-reactive protein and serum amyloid A protein measurement, a significant decline being expected two days after the start of treatment. Patients with extensive pulmonary destruction and high serum amyloid A protein levels remaining after sputum has become negative for $M$ tuberculosis may need broad spectrum antibiotics and active physiotherapy in an attempt to reduce these levels. This might prevent the development of incurable reactive systemic amyloidosis.

The authors wish to thank Dr JM Jenkin and staff of the Brooklyn Chest Hospital, Cape Town, for the provision of certain samples. This work was supported by the South African Medical Research Council.

\section{References}

' Pepys MB. C-reactive protein fifty years on. Lancet 1981;i:653-7.

${ }^{2}$ Benditt EP, Eriksen E. Amyloid protein SAA is associated with high density lipoprotein from human serum. Proc Natl Acad Sci USA 1977;74:4025-8.

${ }^{3}$ Lavie G, Zucker-Franklin D, Franklin EC. Degradation of serum amyloid A protein by surface-associated enzymes of human blood monocytes. J Exp Med 1978;148: 1020-31.

${ }^{4}$ Skogen B, Natvig JB, Borresen AL, Berg K. Degradation of Amyloid-related serum protein SAA by a component present in rabbit and human serum. Scand J Immunol 1980;11:643-8.

${ }^{5}$ Glenner GG. Amyloid deposits and amyloidosis. $N$ Engl J Med 1980;302:1333-43.

- Roantree RJ, Rantz LA. Clinical experience with the C-reactive protein test. AMA Arch Intern Med 1955;96:674-82.

' De Beer FC, Pepys MB. Solid phase immunoradiometric 
assay for C-reactive protein using magnetisable cellulose particles. J Immunol Methods 1982;50:299-308.

${ }^{8}$ Shine B, De Beer FC, Pepys MB. Solid phase radioimmunoassays for C-reactive protein. Clin Chim Acta 1981;117:13-23.

9 De Beer FC, Dyck RF, Pepys MB. Solid phase immunoradiometric assay for serum amyloid A pro- tein using magnetisable cellulose particles. J Immunol Methods 1982;54:213-21.

${ }^{10}$ De Beer FC, Fagan EA, Hughes GRV, Mallya RK, Lanham JG, Pepys MB. Serum amyloid A protein concentration in inflammatory diseases and its relationship to reactive systemic amyloidosis. Lancet 1982;ii:231-4. 